\title{
BIRTHING FROM WITHIN: Nature, Technology, and Self-Making in Silicon Valley Childbearing
}

\author{
ANDREA FORD \\ University of Edinburgh \\ (D) https:/ / orcid.org/0000-0003-0462-9669
}

From week to week I felt my body shift into different cycles, like some slow-motion, flesh-based washing machine ... I did not feel like an animal, I felt like a clock, one made of blood and bone, that you could neither hurry nor delay. ... There was no technology for it: I was the technology.

—Anne Enright, Making Babies

"There are three types of knowing in labor," explained Kristen, the childbirth educator hired to give private lessons to my doula client, Jasmine: "primordial, modern, and self." ' It was a cold, gray summer Saturday in San Francisco's Mission District, and we were seated in the bedroom of Jasmine's tastefully decorated loft apartment, Parisian prints on the exposed brick wall and the sound of her housemate's kitchen tinkering muffled in the next room. A doula is a birth attendant who provides informational, emotional, and physical support, usually beginning during pregnancy and continuing postpartum, but who does not carry medical responsibility. I conducted much of my fieldwork on birth in the Bay Area as a doula.

Jasmine and I faced a large pad of paper leaning on Kristen's easel, where she was writing down the three kinds of knowledge. Primordial she scratched with 
her marker. "This is like a gut feeling. It's something you know without thinking about it." The scent of green tea wafted in from the kitchen, mixing with the marker's sharp chemical aroma. Jasmine stood up to shut the bedroom's French doors against the ruckus of a delivery truck in the alley below, men hollering as they serviced the Thai restaurant downstairs. She swayed from foot to foot as she walked back to her chair, and distractedly stroked her gray tunic where it stretched over her protruding belly, seven months pregnant. Kristen continued to explain "modern knowing" as understanding "logistics," combining a biomedical understanding of physiology with information about risks, tools, options, and protocols within medical care. She waved her freckled hand as if to dismiss this as kind of boring but necessary. Finally, "self-knowing" is "knowing who you are and where you come from. It's knowing what you feel comfortable with, and why," explained Kristen. "This third kind is the most important," she said, "and our session's focus."

This seemed unsurprising to me, since in Silicon Valley birthing culture, childbearing did not simply mean making a new life; it was also a project of making oneself, and, as I have argued elsewhere, of making a world (Ford 2017). Kristen had received her training from the national childbirth education organization called Birthing from Within, which I encountered multiple times during fieldwork. Its curriculum, which incorporates spiritual metaphors like labyrinths to guide parents on their "childbearing journey," encompasses many tropes and assumptions about birth that filtered throughout the Bay Area during my fieldwork from 2013 to 2016. Among the upper middle-class Silicon Valley professionals I worked with, navigating contemporary childbearing was not so much a question of choosing between "technological" or "natural" approaches, of looking either to expertise or to tradition, or of fulfilling gendered and familial expectations, as it was about enacting a personalized process of "self-actualization." In ways specific to this time and place, discovering and enacting the self is a primary way reproduction comes to matter.

This article describes how the cultural and ideological specificities of Silicon Valley and its neoliberal instantiation of feminist empowerment are realized and reinforced through "self-actualized" birthing. Self-actualization is my gloss on phrases I encountered in fieldwork, such as "become your best self," "do what's right for you," and "progress on your journey." Analytically, I discuss self-making as a less morally charged description of the particular theory of self I encountered: a self pre-existing yet optimizable, intensely individual yet grounded in universal human biology, requiring the body but not reducible to it. Here, subject 
and object merge, in ways distinct from earlier analyses of American reproductive embodiment (e.g., E. Martin 2001 [1987]). Discourses about self-actualization can transcend the shaming childbearing people often encounter, tied to accusations of endangering their babies either by not doing things "naturally" enough or by not making adequate use of technology. Yet they also hint at a troubling alienation and suggest the presence of new forms of social pressure.

Birthing from Within's curriculum resonates with Silicon Valley's entrepreneurially minded community, already focused on individualized desires and personal responsibility. In a childbearing context, this focus facilitates the autonomy that has been the rallying cry of activists pushing against regressive gender norms and coercive medical systems - and yet such autonomy can also perpetuate feelings of anxiety and disconnection that pervade neoliberal sociality. The reproductive story I tell here is not simply a new version of the familiar tale wherein a person realizes herself as a proper woman through becoming a (good) mother in a culturally appropriate way (e.g., Paxson 2004). Rather than foregrounding embeddedness in a heterosexual matrix of gender and kinship, these narratives around childbearing share tropes and cultural logics from the Silicon Valley world of innovation, disruption, and entrepreneurial self-making. For this community, then, the cultural significance of childbearing seems to have less to do with realizing gender ideology than with creative self-expression and self-optimization. My decision to use gender-neutral terms in my analytic voice marks not only a political stance, in solidarity with trans/queer politics and to avoid reifying birth as an essential component of womanhood, but a reflection of the gender-neutral virtues that inform Silicon Valley birth culture.

What I find so interesting about Kristen's epistemology is that it is not binary but tripartite. Childbearing people not only navigate the "primordial" and "modern" knowledges Kristen described, but do so by connecting with a "self" that can itself be known and trusted. Although it is in conversation with the long Western history of a dualism between nature and culture, parsing the epistemological conditions of childbearing in terms of primordial, modern, and self-knowing cuts things a different way. It invites childbearing people to be "border creatures," like Donna J. Haraway's (1991) irreverent figures of simians, cyborgs, and women, which are political aspirations and challenging achievements that carry the potential for different ways of being. Cyborgs refuse dualism by emblematizing a chimeric fusion of organic and technological components. Simians present epistemological problems, as primates "like us" yet located across the human-animal divide. Haraway argues that women constitute another liminal figure because they have 
been socially marginalized through association with "base" bodily nature and private emotion (as opposed to intellect and public leadership), yet persistently claim membership in economic, political, and intellectual collectives. Although those I worked with would not explain it in these terms, many of them sought to approach contemporary American childbearing, and its political potential, by crafting themselves as border creatures. To the extent that bearing children within these communities is undertaken as a means toward self-actualization mediated through the design of embodied practices, it foregrounds an emancipatory politics of women's self-determination, while simultaneously advancing a dominant cultural discourse that minimizes thinking about mutual accountability.

In the following, I first set the ethnographic scene for these claims by introducing Silicon Valley, a place rich in both material and symbolic terms, and explaining my dual role as researcher and practicing doula. The second section provides an ethnographic look at how the self in this community is both innate and designed, with interwoven "natural" and "technological" dimensions. The third section elaborates the importance given to self-actualization as a sensibility, aspiration, and moral imperative, arguing that it has effectively become a new rite of passage. The fourth section describes problems with the ideal of self-actualization through childbearing, both in heightening personal anxiety and in advancing a politics of alienation that works alongside concerns about "the human species" in mutually reinforcing ways. Through ethnographic examples, I aim to convey a sense of what "finding one's path" within childbearing looks like for many of those I worked with, while situating Silicon Valley childbearing in a broader history of neoliberalism and feminist activism.

\section{METHOD AND PLACE, ENTANGLED}

Jasmine could not fit a standard childbirth preparation class into her full-time work schedule at a philanthropic investment consultancy. Such courses often meet on weekday evenings for six to eight weeks, and many were already full, so she opted for a private "crash course" over two Saturdays and invited me, her doula, to attend. Birth classes were pricey investments, costing $\$ 200$ to $\$ 600$, and likewise was hiring a doula, which ranged from $\$ 500$ to $\$ 2500$ for a standard package of two prenatal meetings and one postpartum, attendance at the delivery, and four weeks of being on call. ${ }^{2}$ I had met Jasmine through a mutual friend, and this was her first birth; I eventually attended the birth of her second child as well. She was typical of the people I served as a doula (and not unlike myself): well educated, white, middle-class, straight and married, in her early thirties, and actively con- 
cerned with making the "right" sorts of consumer and lifestyle choices (whatever those ultimately ended up being). Although many exceptions to this demographic profile existed in my research, here I am concerned with what might be called a hip elite, a particular iteration of bourgeois sensibility drawing from yuppie, millennial, and hipster trends and colored by Silicon Valley's specific culture. While this sensibility is too particular to be properly hegemonic, it nonetheless proves influential in setting both local and national trends, and responds to the moral and intellectual underpinnings of broader neoliberal developments.

While I do not claim to have encountered a representative sample, my research was varied enough to provide a multifaceted picture of local "childbearing culture." 3 Over nearly three years of fieldwork, I supported around fifteen people as a doula and participated in parent-oriented, professional, and activist activities pertaining to childbearing, including childbirth classes for expectant parents, continuing education for nurses, social salons for doulas, reproductive justice conferences, a breast-pump design meeting, and volunteering in a transitional home for vulnerable childbearing people. I interviewed people I encountered through these activities, followed local and national media, and wrote for a medical blog.

In the United States, a largely privatized health-care system and historical antagonism between midwives and physicians have created rifts and disparities in maternity care. Doctors oversee the vast majority of American births (more than 99 percent), including the roughly 9 percent attended by midwives in hospitals (ACNM 2014); midwifery certification has separate tracks for home and hospital practice, and the systems are poorly integrated (Cheyney 2011). Doulas are supplementary providers whose position evolved in the wake of midwifery professionalization in the 1990s, and insurance does not cover their services. In my analysis, doulas exist as both a niche commodity for bespoke care and an activist platform for birth reform. Put otherwise, they represent both the privatization of health care within neoliberal transformations of public welfare, and grassroots activist pushback against an already privatized, racist, classist, and ineffectual maternity system (see Amnesty International 2011). Questions of access and oversight prove central to deciding what the doula is or should be, and are actively being worked through in doula communities.

Silicon Valley encompasses its own apparent contradictions. It is California's high-tech hub, characterized by innovation and exclusion. Although it originally referred to the South Bay, Silicon Valley has spread up the peninsula to San Francisco, where Jasmine lived, increasingly engulfing much of the East Bay and beyond. In the Bay Area, counterculture and cyberculture grew in each other's 
shadow - natural living through technology was an aspiration, not a contradiction (Turner 2008). The 1960s and 1970s countercultural movement catalyzed Northern California's reputation as a site of utopian possibility, building on the state's role as the American final frontier, since reinforced through speculative fiction and Hollywood (Miller 2013). Immigration, technological saturation, and cultural complexity make Silicon Valley "a microcosm of the social and cultural identities of the future" (English-Lueck 2002, 11). The area is both diverse and exclusive, demographically one-third Asian, one-third white, and one-quarter Hispanic. Nearly 40 percent of residents are foreign born, and 60 percent are under age forty-five (SVIRS 2017, n.d.). People are moving out of the area as quickly as others are moving in, and gentrification is happening at a hyperbolic pace (Walker 2018). Youth culture and eccentricity are valorized, and people approach work as a means of self-expression. California is a trendsetter for the nation (Pastor 2018), and Silicon Valley exemplifies privileged, influential lifestyles imagined as countercultural but in fact fully entwined with neoliberal capital. I use Silicon Valley less as a geographical term than to categorize an aesthetic, moral, and intellectual sensibility tied to this particular place. It is a cultural "project," like America, or the American West.

The natural birth movement of the 1970s has distinguished roots in Bay Area counterculture: Ina May Gaskin, called the mother of modern (white) midwifery, started in San Francisco before caravanning to Tennessee; the Berkeley nurse Peggy Vincent catalyzed hospital midwifery; Santa Cruz midwives were arrested for practicing medicine without a license after starting the first out-of-hospital birth center; and the Marin-based author-activist Suzanne Arms started another such center in Palo Alto shortly thereafter. This push toward the natural in birthing experience was always more political than a rejection of technology itself, emphasizing women's autonomy and solidarity in the face of patriarchal medical institutions (Kline 2016). Meanwhile, researchers at local institutions like Stanford and UC San Francisco continue to develop cutting-edge medical technologies, and Silicon Valley companies are known for offering egg freezing to employees while tech executives boast of eschewing maternity leave after elective caesarians. The Bay Area has long positioned itself as a bridge across the supposed nature/technology binary; indeed, what strikes me is the coexistence of extremes.

A vast array of technologies surrounds the childbearing body in Silicon Valley. High-tech tools - from apps that monitor contractions and track fetal growth, to synthetic hormones and epidural tubing — are available alongside low-tech assistive devices such as large plastic birthing balls or cotton rebozo shawls. Beyond simply offering better diagnosis or treatment, childbearing technologies alter pro- 
fessional responsibilities and relationships, and shape the embodied experiences of all involved (Sandelowski 2000). As Emilia Sanabria (2016, 203) demonstrates in her work on the hormonal body, the false dichotomy between technological "interventions" and natural "non-interventions" is an inadequate (though common) site to evaluate the politics of intervention. Although my interlocutors frequently differentiated between supposedly natural and medicalized approaches to birth, these actors' categories operated as ideals far more than practical realities. The childbearing people I worked with crafted a bricolage that drew from the epistemological, ontological, moral, and bureaucratic claims attached to each approach. The insight that women stake out contingent middle ground in pursuing reproductive care has been a starting point in the anthropology of reproduction at least since Pragmatic Women and Body Politics (Lock and Kaufert 1998), with anthropologists offering critiques of discourses about the "natural" in midwifery (Macdonald 2006) and (over)uses of obstetric technology (Wendland 2008; Morris 2013). My informants took for granted reliable access to emergency technologies such as ambulances and cell phones, which provided an enabling backdrop for the self-fashioning I describe.

Some Americanist anthropology aligns itself with activist birth movements in important ways, offering critiques of mainstream obstetrics and championing midwifery or home birth (Davis-Floyd 2004 [1992]; Cheyney 2011). As a practicing doula, I value the midwifery model and woman-centered care that such anthropology advocates, finding it useful for facilitating positive childbearing experiences within existing feminist politics. (And by doing so according to the conventions of the community in which I was immersed, I participated in the self-making practices I critique here.) However, I aim less to influence maternity care than to demonstrate how childbearing marks a site where cultural tensions are being worked out, following those who have argued that reproduction lies at the center of anthropological concern (e.g., Rapp 2001). Political-economic logics are never set apart from the gendered politics of reproduction (Gal and Kligman 2000; Briggs 2018). Taking up calls for a renewed examination of "medically normal" and "ordinary" pregnancy (Han 2013; Ivry 2015), and for further ethnographic research on hospital birth (Morton 2009), I contend that examining childbearing in Silicon Valley's influential local culture offers a window onto our broader neoliberal moment and the ways of being it encourages. 


\section{THE TECHNOLOGICAL MAKING OF NATURAL BIRTH:}

\section{Designing the Innate}

Jasmine's Birthing from Within course exemplified the pragmatic idealism of Silicon Valley birth culture by critiquing medically managed birth while taking advantage of its presence. Jasmine intended to give birth in a hospital, as do more than 98 percent of Americans, yet she found "natural birth" compelling and wanted to make informed decisions about engaging with medical procedures and technologies. The same held true for nearly all the participants in the four non-hospital childbirth education courses I attended. All my birth experience as a doula was in hospitals, although I interviewed people who had or were planning home births. In the United States, the term natural birth generally refers to an absence of pain medication. It can refer more broadly to the absence of medical technology altogether, or simply to vaginal delivery. Birthing from Within (BFW) is not as prescriptively anti-medical as are some of its contemporaries in childbirth education, such as Hypnobirthing, and it offers classes decidedly broader in scope than those available through most hospitals. It shares many similarities with the enormously popular "mindfulness-based childbirth education" courses I shadowed. All such courses take up the legacy of the 1970s natural birth movement, which critiqued the pathologization and male/medical control of birth, but they also incorporate pushback against older approaches like Lamaze and La Leche League for being too dogmatic and creating shame and guilt around using medical technology, whether by choice or necessity. Birthing from Within serves as an illustrative example of how natural and technological aspects of birth become woven together in Silicon Valley childbearing culture.

Although BFW presumes that its audience is wary of medical intervention, it acknowledges that such interventions can prove highly beneficial "if needed." "Like it or not," BFW's website states, "one of the modern tasks of birth preparation for all parents is to learn about the hospital birth culture in their community," including preparing for medically induced labor and cesarean birth. A fifteen-minute animated film called Elk and the Epidural, presenting the benefits and drawbacks of epidurals (a spinal nerve-block that numbs from the waist down), featured in both Jasmine's course and in a longer-format BFW course at which I assisted. In this fable, a calving Mama Elk encounters difficulties in her labor, decides to have an epidural, and births contentedly in the hospital. The film presents "animal nature," in the figure of the elk, as not only aspirational (in rosy watercolor aesthetics) but also attainable with, not in opposition to, the use of technology. This best-of-bothworlds approach echoes feminist debates over "having it all," while showing the 
supposed distinction between masculine technology and feminine animality to be a false dichotomy. Importantly, race and class privilege is implicit in the appeal of robust animality as a marker of feminine empowerment; the target audience is wealthy Euro-American women historically rendered as fragile and hysterical within patriarchal medical traditions, whereas nonwhite women have frequently seen themselves dehumanized and their physical and emotional pain dismissed (Kapsalis 1997; Briggs 2000).

The epistemological triad of primordial, modern, and self-knowing offered by BFW is haunted by the nature/culture binarism and remains in cultural conversation with a suite of binaries - between organic and technological, instinctual and rational, animal and human, female and male - in resonance with deep-seated Western categorical dualisms (Ortner 1974; MacCormack and Strathern 1980; Descola 2013). Yet when Kristen describes "modern” knowing as "understanding logistics," it extends well beyond simply using technology, while "primordial" knowing indexes an ideological commitment to a specific version of the natural. Moreover, the self-knowing subject foregrounded by the third form of knowledge is necessary for, and indeed produced through, managing both modern and primordial knowing. As they design birth plans and prepare for the labor of birth, childbearing people in Silicon Valley negotiate nature and technology by drawing from both the idea that self-authenticity stems from an unadulterated, primordial nature and that a very modern, reflexive strategy of self-design and self-optimization enables self-realization.

"There's a hormone cocktail in birth that switches moms from left- to rightbrain thinking," Kristen stated later in the course, her blunt-cut hair swinging over her shoulder as she leaned forward to explain. "It's about activating that deep brain stem area, the amygdala, not the prefrontal cortex." According to basic neuroscience, the brain stem is responsible for systemic and motor function, the amygdala for emotions and memory, and the prefrontal cortex for cognition. Kristen presumed Jasmine and I were conversant with such neuroscientific facts, a display of expertise that recruited us as educated insiders while lending her claims epistemological weight. She assumed we had heard that analytic/instrumental thought comes from the left-brain hemisphere, while creative/emotional thought is generated by the right. Both kinds of thinking had a place in the birthing knowledge Kristen was describing. 
According to the BFW website, this "hormone cocktail" functions similarly for all birthing people, moving them from controlled, logical thinking to "labor land," where "instinctual, emotional, intuitive, creative, and meditative" thought reigns. The website describes primordial knowledge as a state of being: "the innate maternal instinct. Women have this knowing in their bones! And they are in this knowing when they are not in their thinking mind!"4 I was surprised by the extent to which the website's language naturalized the trope of Cartesian dualism, locating primordial knowledge in the (female) body and actively opposing it to the rational (male) mind. Yet Kristen's invocation of neuroscience folded these into one another, locating — and validating — both in the birthing brain. Endocrinology functioned similarly, positing hormones as both a site of innate involuntary response and a medium for self-cultivation (many hormones are produced by glands in or near "the brain" and the two discourses are mutually reinforcing). In BFW discourse, one's "self" is always both innate and designed. Biology and culture, nature and technology, the social and the emotional can all be recruited as tools in knowing and making this self. The art of self-making involves knowing which of these tools to use when, and this is precisely what Kristen was coaching Jasmine to do.

To access "labor land," one must put in place conditions conducive to the body's release of oxytocin. Kristen explained that this is why birthing in a calm, safe-feeling environment is important, expounding on a basic theory of hormonal responses I encountered frequently-from doula training, to birthing people explaining their homebirth rationale, to hospital nurses turning the lights down during labor. Essentially, this theory holds that feelings of relaxation and safety are associated with oxytocin, the "love" hormone that facilitates birth physiology, while problematic responses trigger the release of cortisol and adrenaline, the "fight, flight, or freeze" hormones that are mutually reinforcing with stress and fear, and that inhibit birth physiology. To some extent, hormones are considered involuntary biological responses, yet one can learn which hormonal responses are beneficial or not and rationally train oneself, through mindfulness, to be more or less open to their effects. Discourses about nature and instinct supported the desirability of oxytocin, yet a rational subject was required to cultivate such desirable embodied effects.

For example, warnings circulated in childbearing communities about the "cascade of interventions" (in the film, Mama Elk hesitates at the brink of "Epidural Cascading Falls"). According to the "cascade" theory, inducing labor using artificial oxytocin (the drug Pitocin) will bypass the natural physiological oxytocin 
response that causes contractions and simultaneously provides some pain relief. Because the Pitocin-induced contractions will be stronger and more painful, the birthing person may need (or request) an epidural. Epidurals slow labor in part by foreclosing movement, a key "coping strategy" doulas use to keep labor progressing, necessitating an increase in Pitocin. The now hyper-strong contractions cannot be felt by the birthing person but they can distress the fetus, particularly given the absence of calming oxytocin, which it would otherwise receive through the bloodstream. Since indications of fetal distress are cause for C-sections, inductions and epidurals contribute to the American cesarean "epidemic," with rates at around 33 percent (Morris 2013). Because oxytocin also primes both birthing person and newborn for bonding and breastfeeding, these postpartum activities may be compromised. Furthermore, oxytocin released during bonding and breastfeeding stimulates uterine contractions that expel the placenta and halt bleeding, described as an "evolutionary" means of preventing postpartum hemorrhage, a leading cause of maternal death. This theory offers a sophisticated blueprint, based on modern scientific knowing, that childbearing people can use to make informed decisions about birth practices in light of their biologically involuntary, primordially programmed effects.

Self-making requires primordial knowing as well as rationality - that is, cultivating certain kinds of putatively innate awareness. The BFW website explains that social conditioning has taught modern women "not to trust or act on our gut knowing," and therefore, "One of women's modern tasks of pregnancy is to first learn to feel their gut instinct and to distinguish this feeling from fleeting fear (or the contagious fear of others)." Intention and inevitability merge: one can practice accessing and trusting "gut instinct," using the prefrontal cortex to prepare to bypass the prefrontal cortex. "Instinct" becomes simultaneously a goal and a compulsion, as one must learn to disentangle trustworthy, desirable, properly innate instincts from emotional responses caused by external factors. This idea recruits a deeply rooted Western ideology about the interior origins of authentic identity, as opposed to aspects of oneself shaped by relations and context (Foucault 1990; Sadjadi 2019). North American body projects generally concern themselves with revealing one's preexistent personal reality (one's "nature"), as opposed to approaching bodies as "plastic" fields of potentiality (Sanabria 2016, 191). This is evident in the name "Birthing from Within." In the BFW framework, instincts are desirable not because they are biological but because they are internal, and thus linked to personal authenticity. The cortisol panic response, although equally 
biological, is not valorized, in part because it is seen as resulting from external factors.

Yet in contrast to the pediatric gender clinics Sahar Sadjadi (2019) describes, BFW does not consider identity a passive truth waiting to be revealed (waiting in the brain, which is dematerialized and opposed to the body). Rather, the active and ongoing process of seeking to know oneself equally forms part of one's identity. This idea is influenced by the cultural prestige of technology-based design and optimization within Silicon Valley, and by scientific frontiers in which biology is itself a technology (Franklin 2013). This does not suggest that bodies are understood as malleable in the way they are for the Brazilian hormone users Sanabria (2016) describes; self-design is not about crafting one's materiality within social relations, but rather about creating the proper conditions for internal truth to emerge. Biology, whether articulated in terms of brains or hormones, does not so much constitute a medium as a conduit. It is a means to authenticity, digging into personal depths by digging into evolutionary depths (discussed below) and reconciling them within modern technological contexts. Importantly, primordial biology is not an end in itself. The contemporary self-aware birthing person is neither animaldriven by instincts and evolutionarily set hormone patterns, as epitomized in some biocultural approaches and unassisted "free birth" — nor machine, overridden by technological rationalization, as in the figure of the scheduled cesarean." Rather, this "border figure" wields both instinct and rationality in service of actualizing an authentic, optimized self.

Key to this project is self-knowledge, BFW's name for a managerial ability that entails self-discipline, self-awareness, and self-confidence. Self-knowledge is needed to override problematic emotional-biological responses. Instructors at both the longer-format BFW class and the mindfulness-based class emphasized the importance of a meditative mental state to enable "non-reactive behavior." Such meditative presence is neither instinctual nor analytic, but describes a sort of emotional transcendence. The other BFW instructor, Janice, explained "reactions" as defenses, and since a properly cultivated birthing space was safe, a birthing person had no need for defensiveness. However, she said, "your body doesn't know that. . . Y You can't think clearly when the brain is flooded with adrenaline." Likewise, when Kristen described the amygdala, she implied that its functioning would sometimes need to be overridden. Self-knowledge included confidently directing the social situation, which Janice encouraged birthing people to do by "calmly working out problems" from their meditative state, without either creating or avoiding conflict, nor speaking from a place of wanting to appease. By deliberately 
managing one's affect, one could also manage one's hormones and brain, which in turn influenced one's rational faculties and enabled practical action.

The locus of the self is quite slippery here, a moving target that shuttles between being designed and being innate. The embodied self is a feedback loop between process and product, subject and object, transcendence and immanence, and the personal dexterity needed to navigate contemporary birthing has to account for this complex "lived body" (Lock and Farquhar 2007). Silicon Valley childbearing constitutes a management project premised on a sophisticated understanding of sociotechnical logistics, an attunement to one's material biophysical functions, and a quasi-spiritual self-awareness. These capacities are not at odds but interdependent, looping through each other like a Möbius strip (Grosz 1994). As with people diagnosed with depression and confronted with their brain-scan images in Joseph Dumit's (2003) "Is It Me or My Brain?" who work through the slippage in whether and how one's brain is or is not one's self by invoking (and then transgressing) dualistic understandings of mind-body, so too do childbearing people use dualistic terms to describe this management project. Cultural categories are dynamic and blurry yet constitutive of the ways people navigate and change their world.

\section{A NEW RITE OF PASSAGE}

"We support women — what the mother wants is our priority," asserted my doula training instructor. Being a doula was, in theory, not about furthering our own agendas for a "good birth," or following any prescribed course of action. As service providers, we were to help the birthing person identify her own desires by providing information and opportunities for reflection, and to mediate between her, her partner and family, and hospital staff to help realize those desires. Like most of the women who asked me to be their doula, Jasmine did so because she wanted "support." As a doula, figuring out how to be supportive and not directive involved asking, listening to, and observing what a person wanted. Navigating childbearing decisions and practices was not so much a question of seeking expert advice or following in the footsteps of friends or family as it was one of introspection and choosing "a path that's right for me," in Jasmine's words. Crafting such a path has two aims: childbearing people (and their doulas) have to manage not only birth (toward the desired outcome of a healthy baby) but also the meanings of the "birth experience" toward a feeling of self-actualization. The achievement of this feeling is aspirational, but within the community examined here, the compulsion to seek it is normative to the extent of marking a rite of passage. 
Practitioners on the medical periphery, such as doulas and childbirth educators, often declined to be overtly prescriptive while attending closely to the process, and outcome, of others' decision-making. Childbearing people were encouraged, even pressured, by online media and their peers to make their own choices and have opinions, even when they were not particularly interested in doing so. "Non-directed" decision-making reflects dominant Euro-American ideas of agency and consent (see Tine Gammeltoft's [2014] contrast with Vietnamese practices of collective decision-making). Yet its "non-optional" status levies judgment of its own. Discourse about making the "right" choices could certainly prove moralizing (e.g., Lyerly 2006), even in ostensibly supportive reassurances that C-sections or formula feeding did not amount to personal failures, but those among whom I worked generally held that childbearing people should be judged not for their choices but for the process by which they make them.

Not only does this stance presume that various options are accessible at will, which is not the case for most people (the way medical technologies are often forced or withheld in racialized ways is only the tip of this iceberg, as detailed by reproductive justice scholars critiquing "choice," e.g., Roberts 1997). It also presumes that people have the time, energy, and money to spend crafting their approach and themselves. I was particularly struck by this when volunteering at the transitional home for vulnerable childbearing people, where clients needed much more practical assistance than help identifying their desires. Recognizing ways my middle-class doula preparation proved largely irrelevant brought into relief how centered it was around shaping such an "appropriate" childbearing subjectivity. This pressure to take a stance (even if hypothetical) was also highlighted in an interview with a timid, middle-class pregnant person who was deferential to her husband and parents, and expressed concern over her difficulty formulating opinions about her upcoming birth.

Two rituals within this rite of passage stand out to me as emblematizing the aspects of design and innateness constitutive of self-making: birth plans and labor land. Both are codified, meaning-laden ways of marking a transition from a less-actualized to a more-actualized self (understood as the basis for becoming a "better" mother and woman). As rituals, they serve a performative and not merely instrumental function, recursively drawing the birthing person's attention to the meaningfulness of the process itself, apart from the outcome.

In developing a birth plan, a childbearing person decides ahead of time what procedures they want to happen in the birth room, usually as a result of research, counseling, and introspection, often facilitated by a doula. Increasingly, these ideas 
are being called "birth wishes" rather than "plans" to acknowledge unpredictability - a reframing that is less conducive to disappointment but that also suggests its performative role. People wrote such lists to express their deliberative personal desires, but ironically, the actual plans tended to resemble each other. As an obstetrician observed in a 2016 Slate article, "Everyone and her mother now wants skinto-skin and delayed cord clamping," referring to placing the newborn directly on the birthing person's chest after delivery, before cleaning and wrapping, and waiting to clamp and cut the umbilical cord until it stops pumping blood into the baby (Austin 2016). Indeed, Jasmine's birth plan included both items. Other aspects of the birth plan were more personalized, such as whether nurses should offer pain medication, whether to watch the delivery with a mirror, what to do with the placenta, who would cut the umbilical cord, or about bringing speakers, pillows, or lights from home. When I started fieldwork in 2013, birth plans seemed nearly ubiquitous as a ritual marking the work a childbearing person had done toward becoming more self-actualized; as a doula, I discussed a relatively standard list of possible procedures with clients, including to what lengths they would go (or like me to go) to assert agency over what happened in the birth room. Birth plans are less common today in 2020, due largely to the evidence-based adoption of many commonly requested birthing options into routine hospital procedures, which increasingly articulate a middle ground between highly medical and nonmedical birth.

The animalistic state Kristen referred to as "labor land" equally forms part of this new rite of passage. Generally, this meant feeling the intensity of unmedicated labor for a period of time, but it did not have to last for the entire birthing process; strength and self-awareness could be indicated by knowing when one had had enough primal experience and wanted an epidural, as well as by stubborn endurance. Many doulas and midwives I spoke with extolled the beauty and power of "primal," "instinctive," and "animal” states during labor, characterizing them in terms of internal awareness, spiritual intensity, and disregard for social and cultural conventions. Alzbeta, an experienced doula, offered this explanation when asked about "labor land":

It's that place where you really need to get out of your head and go within. Just work with it. Go with the flow, and don't go against it. And I dunno if that's the right terminology, calling it labor land, but definitely I've seen it. An animal instinct. You'll ask a lot of women, they'll say, "Oh my gosh,” or 
the partner will say, "She's gone to that place, and it was really surprising, but she went there."

Explaining that "we are taught in our culture to stay in our frontal brain," she called it a sacred and beautiful thing to trust instead in a knowing body: "Don't try to analyze, just let go and let your body do it."

Dani, whom I interviewed shortly after she gave birth in a hospital — without medication and with a midwife - referenced animality at multiple points in our conversation. For her, animality meant an emphasis on physicality and immediacy.

Dani: [My midwife] said she saw a laboring goat one time and it just wanted to ram its head up against a wall. That was me. I just wanted someone to push my head really hard.

Me: How was your brain working when you were in labor?

Dani: I was like an animal. I kinda describe it as like, you know how dogs want to just crawl into the backyard and die under a bush by themselves? That's what it felt like my labor experience was! [Laugh] I didn't want any light, I didn't want any major stimulation, closed curtains, turned off all lights ... I did not want to know what time it was . . so that's what I mean animalistic, just intensely present to what was going on right there.

Open-mouthed, guttural "animal" noises very much formed a part of birthing, sounding out everywhere from doula training, to births I attended, to a singing circle for pregnant people and birth workers. Once, in a childbirth class at which I was assisting, I was asked to playact a person in labor, and making grunting or moaning noises was foremost among the trainer's requests. These ritualistic behaviors help generate the experience of self-actualization precisely because the animalistic is framed as essentially human.

Along with noisemaking, nudity seemed almost inevitable; laboring people would gradually cease to care about tugging their hospital gown into place, and my assisting them while they showered and used the toilet quickly became a commonsense intimacy. I watched hospital practitioners discreetly remove feces produced during pushing, sometimes sprinkling peppermint oil to cover the scent. I have a poignant memory of another client, Molly, squatting flushed and naked on a "birth stool," a low chair with a hole cut in its seat. Her midwife's ponytail brushed the linoleum as she practically laid her head on the hospital room floor, watching Molly's vulva and encouraging her. Molly had been pushing for nearly two hours, 
her trembling, glowing body clinging between triumph and exhaustion. Yet there was something incongruous and even ridiculous about the scene, settled against its backdrop of computerized bureaucracy and orderly generic decor. Here, nudity is embraced as a sign and symptom of tapping into primordial power, a far cry from the infantilization of the shaved pubic area Robbie Davis-Floyd (2004 [1992]) describes of decades past, yet such power must exist in modern contexts. Reconciling these contrasts is part of ritual self-making. Just as the birth plan's significance is more about design than implementation, labor land concerns the personal development needed to "go there" and release into one's innate animality, while still being connected to high-tech surroundings.

Although she rejected the term labor land, Dani described her unmedicated birthing experience as visiting another world, using intense spiritual terms:

Labor Land sounds like Candy Land, sounds like something really light. I've been describing it as I went to Hell. It's birth hell, it's totally birth hell. Going to the moon and back. It's like intergalactic travel. But it really is like going to the underworld and bringing a baby back. You have to go down, you have to meet the devil ... shake his hand and do a little dance, and yeah, then you have to climb back up from Hades. ... Oh, yeah, and bleed like hell. It was very Grecian, like otherworldly.

Spirituality was frequently invoked to frame this foray into the nonrational. Biology, animality, and the primordial are all understood as universal human attributes, but the process by which one accesses such attributes is specific to one's personal "journey" inward. Although this journey is considered deeply human, it marks a radical departure from conventional sociality. In Alzbeta's words, "Ignore everyone around you, think 'I don't care." To some extent, this departure is framed in gendered terms. Midwives and doulas often marked the primal state as essentially female, capable of catalyzing a specifically feminine spiritual transformation (see Gaskin 2002 [1975]). Animal metaphors and appeals to supernatural forces can facilitate a female experience that exists beyond the social constraints of gender propriety. Yet the rituals of self-making I am describing are not primarily concerned with producing womanhood correctly, much less social identities as "good" wives or mothers; rather, they foreground a person operating at the height of her capacities by skillfully drawing on the human qualities of rationality and animality.

When people like Jasmine craft childbearing selves, their choices come attached to ideologies; self-narration drawing on these ideologies forms part of rit- 
ual self-making. Childbearing people often explained their practices to me using phrases like, "that's just how I approach life," or "I'm going to do [x] but I'm not ashamed to have [y]," or "I'm doing [z], but I'm not that kind of person." Dani differentiated herself from both a close friend and her sister, saying she and her partner "went the traditional medical Western route" because they birthed in a hospital and accepted various tests. Her partner explained how their friends, despite many similarities in their lives, "chose to go, like, total hippie style. They never had a sonogram, basically didn't enter a Western medical facility at all." They then described how Dani's sister had a home birth but was "not as hippie [as either themselves or their friends] . . they're watching the Giants' game right now, they're more mainstream, they're young people, they party, they're hip, they're not, like, political."

Because choices are seen to reflect and reinforce personal identities, the process by which one makes and advocates for them must be based in self-knowledge. Brigitte Jordan's (1993 [1978]) Birth in Four Cultures introduced the concept of "authoritative knowledge" to describe institutional, professional forms of knowing about birth and women's bodies. The concept has been used to reclaim intuitive, relational knowledge (Davis-Floyd and Sargent 1997) and is often contrasted with "experiential knowledge" that draws on cultural tradition and the experiences of friends and family (Abel and Browner 1998). Yet neither the "authoritative knowledge" of experts nor the "experiential knowledge" communicated through traditional practice is deemed sufficient to guide one through the thicket of birth choices available to this community. The pressure childbearing people felt to become informed about medical/scientific evidence is not the same as unreflectively submitting to medical expertise. A popular website, EvidenceBasedBirth.com, produces curated reports of biomedical studies on hot-topic issues and encourages people to bring the reports to their next provider appointment, stating that "informed, empowered choices" will yield "the positive birth you deserve!" (Dekker n.d.). This exceeds the "educated consumer" model by promising fulfillment on a more existential level.

Similarly, I rarely heard anyone explain their choices with reference to cultural tradition. Some people invoked family traditions, like gifting a particular kind of teddy or using a heritage cradle, but not received wisdom about how to undergo childbearing. Accepting help from parents and in-laws was often coupled with strategies for maintaining personal space and defending one's preferences. Stanford Medicine offered a course for new grandparents, teaching them, basically, to back down and respect their children's choices as parents. While some may feel 
removed from familial and cultural traditions for reasons of geographic and class mobility or generational length, here I am pointing to the cultural pressure to self-invent by crafting personally meaningful rituals and making "new traditions." For example, so-called blessingways were promoted in my doula training and practiced by several people I interviewed; these appropriate a Navajo custom (generally uncredited) and entail a gathering of friends and family to bless the pregnant person via newly invented rituals like group singing or making bracelets to wear until the baby is born. In Silicon Valley generally, knowledge accrues authority less from established institutions or heritage than from claims to being innovative, disruptive, and original. ${ }^{5}$ Echoing the reproductive-rights rallying cry, "woman is the authority on her own body," becoming an authority on oneself is forwarded as a moral and social imperative, part of a ritual framework toward becoming a more fully developed, self-aware, and empowered person.

\section{THE LIMITS OF SELF-AUTHORITY}

Childbearing people in Silicon Valley are presented with the idea that crafting one's birth experience constitutes an act of self-discovery and, ultimately, of self-actualization, but in taking up that project they might fail as often as they succeed. People I spoke with weighed circulating ideals against the constraints and imperatives of their own lives and lifestyles. Being adamant about not having an epidural or cesarean could align with having several rounds of egg extraction and in-vitro fertilization. People made such compromises from positions of great privilege, and even then making it all work out appeared stressful. Similar to how Emily Abel and Carole Browner (1998) describe women's "selective compliance" with medical authority, I saw "selective compliance" with an idealized "self-authority." People's resolve wavered, and their opinions could fluctuate under shifting influences, pushing them to seek certainty elsewhere. The pressure for every woman to chart her own path and make decisions "from within" can be intimidating, particularly when one has little experience of childbearing and is unsure of what is actually possible. In part, doulas are a response to this reality. Everyone wanted "what's best for baby" — but it was not always obvious what that was, or what the childbearing person's own desires had to do with it. Similarly, the injunction to design the proper conditions for "natural capacities" to emerge led to feelings of failure if one's body did not rise to the occasion. The reflexive self-making described above is not easy to realize in practice.

As childbearing decisions become practices of self-actualization, they also become ways of doing feminism, producing a less-gendered womanhood, and making 
reproduction matter - that is to say, they become political. In this sense, they are Foucauldian "techniques of the self" (Foucault 1988). Yet the way self-actualization circulates as a discourse is notably depoliticized, supposedly "just" about oneself. This is both a way of not acknowledging the structural and material constraints on making and realizing one's choices, and a means of disconnecting from relationships, traditions, and responsibilities that might make claims on oneself but might also provide guidance and reassurance. It is precisely because the material and social conditions that interfere with self-actualization are sidelined from the self-making feedback loop that the whole project is not only untenable, and therefore anxiety-provoking at a personal level, but can resonate with feelings of alienation and disempowerment ratcheted up to the species level.

Both of these issues are illustrated beautifully by a breast-pump user experience meeting I attended. Jasmine experienced the postpartum period after her first child's birth as full of anxieties about returning to work, producing and pumping milk, and the baby's weight. Anxious memories of this time overshadowed preparations for the birth of her second child. When I encountered a Silicon Valley tech startup founded by three Stanford graduates designing a better breast pump and looking for moms to talk to, I connected them with Jasmine. Later, I myself attended a meeting to brainstorm design goals for their nascent product. The meeting was held at an incubator that helps launch San Francisco tech startups by providing them a workspace, funding, and mentorship. I arrived at the refurbished warehouse in the gentrifying, techie SOMA district, with its banged-up metal door and rusty railings, and checked in on a sleek iPad. Piles of electronics were strewn across tables filling the open main space. In a smaller meeting room, pump prototypes of silicone cups and tubing were set out, and refreshments included varieties of Mrs. Patel's Lactation Treats and Teas made with fenugreek seed to stimulate milk production, a gesture toward both the herbal medicine of the white natural birth movement and the prominence of South Asian immigrant cultures in Silicon Valley. The other six attendees were nursing mothers.

Infant feeding is a morally and emotionally charged issue (often reduced to questions of breast milk versus formula, though there are myriad hybrid practices) among white, educated, and/or middle-class communities. Logistical difficulties accompany breastfeeding while maintaining a professional life, as Jasmine did, in addition to a swath of anxieties and frustrations about one's ability to produce adequate breastmilk. Both concerns were projected onto the fantasy pump we were envisioning. Attendees said it should ideally work under clothing, with people around, and while doing something else (multitasking seemed essential). It should 
be easy to clean with few parts and crevices, simple to use with no instructions, and have mix-and-match components to suit various outfits and contexts. Perhaps it could sense when it was set up incorrectly and alert the user, and come with a nightlight. They emphasized that it must be a stress reducer, not a stress enhancer. Particularly interesting was talk of an accompanying mobile app to track data and provide moral support, offering a virtual "high five" and letting the user know how much milk had been pumped_-although attendees worried such information might be "crushing" should the volume prove less than usual. The app offered a kind of technological intuition, as these nursing people not only hoped it might assuage feelings of failure and guilt but also help them relax and "connect with the baby's needs" through tracking, praise, reminders, and education- "like a baby health Fitbit." This breast pump was to be a personalized tool tailored to one's own biometrics and emotions.

When paid labor often separates childbearing people from their babies, yet the virtues of breastfeeding are extolled - from the U.S. Surgeon General's Call to Action (U.S. Department of Health and Human Services 2011) to the rise of "militant lactivism" (Faircloth 2013)_ breast pumps make for a crucial technology. They contain contradictory politics, blurring domestic work and paid labor in a way that creates "more work for mother" (Boyer and Boswell-Penc 2010), and providing more mobility and freedom to users while also perpetuating the exceptional absence of guaranteed maternity leave in the United States. At the UX meeting, we did not discuss maternity leave policies or employer accommodations for pumping. Nor were questions of affordability addressed; when I asked what price point the developers anticipated, the range given was out of reach for most American families. The quest for an individualized, exclusive, technical solution for a problem that might otherwise be solved by collectively restructuring working conditions, gender relations, and state responsibility illustrates the neoliberal context in which self-actualization is valorized. The UX meeting exemplifies how pressure to craft oneself results in personal anxieties about failure, and eclipses structural and social issues on which enacting desires depends.

In the circles I moved in during fieldwork, rhetoric about humans writ large could take on apocalyptic tones, echoing epochal anxieties about the Anthropocene and technological modernity's negative effects, often via nostalgia for an imagined past purity. Michel Odent's (2014) Childbirth and the Evolution of Homo Sapiens is emblematic. In it, the French obstetrician blames C-sections, inductions, and other medical interventions into the "oxytocin system" for population-wide problems with autoimmune, metabolic, and affective disorders, extrapolating the 
stakes of "bad" birth choices to the fate of the species. Discourses of "paleo-parenting," similar in practice and intellectual heritage to popular attachment-parenting philosophies, recruit evolution to advocate for particular cultural practices, such as extended breastfeeding, baby wearing, and co-sleeping. The primordial knowledge discussed above is related to this, but while that emphasized looking within, the aspect I am pointing to here emphasizes looking behind. Looking to primates as bearers of biological truth - and to human cultural arrangements supposedly closer to primate life_- evoke evolutionary narratives in the service of self-optimization. They look to the deep past to locate a form of truth in human origins, one usually disconnected from the sort of relational issues that might make claims on someone in the present. At least in Silicon Valley, the primordial is not the 1970s version of nature, which evoked anticonsumerism, informal communality, spirituality, harmonizing with the outdoors, and allowing the body to do what it will. Nor is it ecofeminism, foregrounding ecological and intergenerational relations and their concomitant responsibilities. Rather, as described above, the primordial invokes pop neuroscience and the idea that certain traits or processes are hard-wired into generic individuals, downplaying the role of society or cultural particularity. It is more about instinct than intuition, in that it is framed as something both universal and inherent to individuals, rather than cultivated through particular experiences in an interconnected world.

This take on nature lies at the root of other popular trends in Silicon Valley and elsewhere, such as paleo diets and barefoot running. Such "modern primitivism" is further consistent with transhumanist practices like biometric tracking or biohacking (Schüll 2016). What links them and makes them distinct from how nature and technology coincided in 1970s Silicon Valley is a focus on self-optimization. This self-optimization resembles the self-making discussed above in that it is achieved through managing logistics well and in keeping with one's essential nature, but it heightens anxiety by suggesting the existence of a best way to do so. The breast pump app and its "baby Fitbit" capacities align with this trend. For the people I worked with, such rhetoric both fueled their anxiety by elevating the stakes of their decisions and provided much-desired guidance.

\section{CONCLUSION}

The fantasy breast pump encapsulates the political aspirations at stake in this version of self-making. It would seamlessly meld into the childbearing person's physical and emotional contours, enhancing her capabilities and fortifying her wellness, while feeling "like skin on skin" instead of being hooked to a machine. 
In this imaginary, the nursing person is a Harawayian cyborg, empowered by relationship to a machine. Likewise, mammalian functioning is desirable not via comparison with the denigrated animality of livestock - nursing people did not want to feel reproductively harnessed, "like a cow," when using the breast pump - but instead the primordial version represented by the noble wild elk and experienced as naked power. The pump would produce new embodied possibilities - in many ways, new possibilities for being a woman - in a historical context of feminism in which both the mechanical and the fleshly have been simultaneously romanticized and disparaged.

New social possibilities for womanhood are at stake as well. For childbearing people in contemporary Silicon Valley and elsewhere, bearing and raising children may be increasingly oriented toward "having the experience" (or not) of enacting a sense of self through the process of maternity and parenting, rather than fulfilling kin-based responsibilities and gendered expectations or forging important filial ties. ${ }^{6}$ Cultural artifacts such as Sheila Heti's (2018) acclaimed novel/memoir, Motherhood, poignantly illustrate an approach to procreation framed as a project of creative self-actualization. We can read a similar push toward self-actualization via personalized optimization in the recent pressure for elite women to freeze their eggs while they are relatively young — something numerous Silicon Valley companies have offered to subsidize for employees as a workplace benefit. Timing childbearing in career trajectories marks a contemporary negotiation of "having it all," when having children itself is no longer a necessary rite of passage for adulthood, and might be seen as equally or less important than a career as a means for crafting one's identity.

Childbirth in Silicon Valley today entails rationally navigating technological and social options in ways consistent with a primordial nature that itself exceeds the terms of rational thought, a project described as self-actualization. A good birth, then, is one in which a birthing person realizes themselves as agentive in a particular way: as both thoughtfully in control and able to tap into their inner animality by setting the proper conditions for it to emerge. A cultural emphasis on personal agency here responds to a history of misogyny in hospital reproductive care; it can also neutralize dogmatic ideas about natural versus medical approaches that have been used to shame and coerce women, and shifts focus off the fetus/ baby, whose supposed interests can eclipse those of the mother in reproductive politics (Bordo 2004). Yet a cultural focus on self-actualization also diverts attention from (and perpetuates) the social and structural pressure put on mothers to act as the sole fount of security in an insecure world (Villalobos 2014). Moreover, 
the elite self-making I describe is shadowed by the curtailed motherhood of those struggling with homelessness, drug abuse, incarceration, and economic precarity prominent in the Bay Area, and speaks to its politics of extremes (Knight 2015; Sufrin 2017). There are fundamental prerogatives that many childbearing people cannot take for granted, from being listened to and having one's pain taken seriously, to having access to health care and a safe home. Recent reporting about the United States' abysmally high rate of maternal mortality, deeply marked by racial disparities, is bringing this reality into broader awareness (N. Martin et al. 2017; Villarosa 2018).

Silicon Valley's and BFW's shared emphasis on individualized desires, self-awareness, and personal responsibility as, in Kristen's words, the "most important kind of knowledge" advances a social politics of non-relationship, of being not-accountable for each other-which, from a position of privilege, can look like autonomy. Yet anxieties about an uncertain future beyond any individual's control or influence haunt this sort of autonomy, perhaps in a mutually reinforcing way. In his study of U.S. affect since the Cold War, Joseph Masco (2006) argues that technological fallout creates complex problems that exceed existing social forms (such as the nation or the family), take on momentum of their own, and bewilder people's sensory capacity to perceive and negotiate risk; consequently, practices of everyday life are based on insulating oneself from one's environment, not engaging it. Turning inward could be seen as a reasonable response in the face of a future that seems out of one's control; hyper-focus on one's personal decisions could go hand in hand with a sense of disempowerment and social alienation. In her recent provocation to "make kin, not babies," Haraway (2016) advocates shifting focus (back) to relationality and kinship in response to planet-level problems, but in nonhegemonic ways that have little to do with birthing babies into nuclear families and more to do with making allies toward a livable future (see also Clarke and Haraway 2018). Loosening the creative power of childbearing from its place in patriarchal, settler, extractive gender formations could prove a step toward this end, if we could embed the personal cultivation encouraged in Silicon Valley childbearing in other, more collectively promising social, ecological, and political formations.

\footnotetext{
ABSTRACT

Through examining childbearing in California's Silicon Valley, this article describes how seeking "self-actualization" has become a rite of passage for contemporary childbearing people. This approach undermines distinctions between "technological" and
} 
"natural" approaches to birth, as people are coached to leverage both logistical and animalistic capacities to produce "self-knowledge" and enact new feminist ways of doing embodiment. Based on fieldwork conducted as a doula, this article describes new rituals, anxieties, and aspirations that draw from both the idea that self-authenticity stems from an unadulterated, primordial nature and that self-realization is enabled by a very modern, reflexive strategy of self-design. In this community, the way reproduction comes to matter has less to do with realizing gendered expectations and kinship relations than with creative self-optimization. This approach facilitates women's self-determination, while simultaneously introducing new forms of pressure and advancing a dominant cultural discourse that minimizes thinking about structural conditions and mutual accountability. [childbearing; birth; doula; United States; Silicon Valley; neoliberal subject; nature/culture; selfhood; rite of passage]

\section{NOTES}

Acknowledgments I offer my sincere thanks to the many people who have contributed their insight, encouragement, and experience to crafting this essay. This includes colleagues at the University of Chicago who read early drafts: Amy McLachlan, Erin Moore, Victoria Nguyen, Ali Feser, Matthew Furlong, Nicholas Carby-Denning, Jeremy Siegman, Meghan Morris, and Eric Hirsch. Many thanks to Judy Farquhar, Joe Masco, Julie Chu, and Susan Gal for their guidance and inspiration, and also to the department at UC Santa Cruz for their warm welcome, particularly to Megan Moodie, Donna Haraway, and Nancy Chen. I am grateful for the thoughtful suggestions made by the anonymous reviewers for Cultural Anthropology, and especially for the brilliant editorial work of Heather Paxson. The research for this article was supported in part by the Harper and Watkins Fellowships at the University of Chicago and the Wellcome Trust, through grant number 209519/Z/17/Z. It was made possible by the generosity of friends, family, and childbirth communities in California, to whom I am deeply grateful.

1. Pseudonyms used throughout.

2. These numbers reflect prices in 2015. Many doulas offered sliding scales, and volunteer programs existed for underresourced communities.

3. A 2016 study cites about 10 percent of California births as attended by a doula, with nearly 40 percent of respondents expressing interest, percentages likely much higher in the "hip elite" Bay Area demographic (Sakala et al. 2016).

4. The language was updated in 2019 to change maternal to parental, and women to people, in line with the less gendered framing I am describing. "Three Kinds of Knowing," Birthing from Within (blog) (accessed May 18, 2018); updated 2019 to "12 Ways to Change Birth in Our Culture: Cultivate Three Ways of Knowing," Birthing from Within (blog), July 22, https://birthingfromwithin.com/three-ways-knowing/.

5. Jordan, educated in California, later worked for the Silicon Valley R \& D company Xerox PARC, and applied the concept of authoritative knowledge there.

6. Silicon Valley and California birth rates have declined significantly since 2008 (down 13 percent and 14 percent, respectively), and were lower in 2016 than in any year since the mid-1980s (SVIRS 2017).

\section{REFERENCES}

Abel, Emily K., and Carole H. Browner

1998 "Selective Compliance with Biomedical Authority and the Uses of Experiential Knowledge." In Pragmatic Women and Body Politics, edited by Margaret Lock and Patricia A. Kaufert, 310-26. Cambridge, UK: Cambridge University. 
ACNM (American College of Nurse-Midwives)

2014 "Fact Sheet: CNM/CM-attended Birth Statistics in the United States." www. midwife.org/acnm/files/ccLibraryFiles/Filename/000000005950/CNM-CMAttendedBirths-2014-031416FINAL.pdf.

Amnesty International

2011 "Deadly Delivery: The Maternal Health Care Crisis in the USA: One Year Update, Spring 2011.” Amnesty International, May 7. https://www.amnestyusa.org/

Austin, Jennifer reports/deadly-delivery-the-maternal-health-care-crisis-in-the-usa/.

2016 “Forget What You've Read: Dousing Your Baby with Vaginal Juices Is Pointless and Weird" Slate, February 10. https://slate.com/human-interest/2016/02/dousing-

Bordo, Susan your-newborn-in-vaginal-juices-is-pointless-and-weird.html.

2004 "Are Mothers Persons? Reproductive Rights and the Politics of Subjectivity." In Unbearable Weight: Feminism, Western Culture, and the Body, 71-98. Berkeley: University of California.

Boyer, Kate, and Maia Boswell-Penc

2010 “Breast Pumps: A Feminist Technology, or (Yet) 'More Work for Mother'?" In Feminist Technology, edited by Linda L. Layne, Sharra Vostral, and Kate Boyer, 119-35. Urbana: University of Illinois.

Briggs, Laura

2000 "The Race of Hysteria: 'Overcivilization' and the 'Savage' Woman in Late Nineteenth-Century Obstetrics and Gynecology.” American Quarterly 52, no. 2: 246-73. https://www.jstor.org/stable/30041838.

2018 How All Politics Became Reproductive Politics: From Welfare Reform to Foreclosure to Trump. Oakland: University of California Press.

Cheyney, Melissa

2011 Born at Home: The Biological, Cultural, and Political Dimensions of Maternity Care in the United States. Belmont, Calif.: Wadsworth Cengage.

Clarke, Adele, and Donna Haraway, eds.

2018 Making Kin Not Population: Reconceiving Generations. Chicago: Prickly Paradigm.

Davis-Floyd, Robbie E.

2004 Birth as an American Rite of Passage. 2nd ed. Berkeley: University of California. Originally published in 1992.

Davis-Floyd, Robbie E., and Carolyn F. Sargent

1997 Childbirth and Authoritative Knowledge: Cross-Cultural Perspectives. Berkeley: University of California Press.

Dekker, Rebecca

n.d. "Resources for Parents." Evidence Based Birth. Accessed November 8, 2019. https:// evidencebasedbirth.com/resources-for-parents/.

Descola, Philippe

2013 Beyond Nature and Culture. Translated by Janet Lloyd. Chicago: University of

Dumit, Joseph Chicago Press.

2003 "Is It Me or My Brain? Depression and Neuroscientific Facts." Journal of Medical Humanities 24, nos. 1-2: 35-47. https://doi.org/10.1023/A:1021353631347.

English-Lueck, J. A.

2002 Cultures@SiliconValley. Stanford, Calif.: Stanford University Press.

Faircloth, Charlotte

2013 Militant Lactivism? Attachment Parenting and Intensive Motherhood in the UK and France. London: Berghahn.

Ford, Andrea

2017 "Near Birth: Gendered Politics, Embodied Ecologies, and Ethical Futures in Californian Childbearing." PhD diss., University of Chicago. 
Foucault, Michel

1988 "Technologies of the Self." In Technologies of the Self: A Seminar with Michel Foucault, edited by Luther H. Martin, Huck Gutman, and Patrick H. Hutton, 16-49. Amherst: University of Massachusetts Press.

1990 The History of Sexuality: Volume 1: An Introduction. Translated by Robert Hurley. Franklin, Sarah New York: Vintage. Originally published in 1978.

2013 Biological Relatives: IVF, Stem Cells, and the Future of Kinship. Durham, N.C.: Duke University.

Gal, Susan, and Gail Kligman, eds.

2000 Reproducing Gender: Politics, Publics, and Everyday Life after Socialism. Princeton, N.J.: Princeton University.

Gammeltoft, Tine M.

2014 Haunting Images: A Cultural Account of Selective Reproduction in Vietnam. Berkeley: University of California Press.

Gaskin, Ina May

2002 Spiritual Midwifery. 4th ed. Summertown, Tenn.: Book Publishing Company. Originally published in 1975.

Grosz, Elizabeth

1994 Volatile Bodies: Toward a Corporeal Feminism. Bloomington: Indiana University Press.

Han, Sallie

2013 Pregnancy in Practice: Expectation and Experience in the Contemporary US. New York: Berghahn Books.

Haraway, Donna J.

1991 Simians, Cyborgs, and Women: The Reinvention of Nature. New York: Routledge.

2016 Staying with the Trouble: Making Kin in the Chthulucene. Durham, N.C.: Duke University.

Heti, Sheila

2018 Motherhood: A Novel. New York: Henry Holt.

Ivry, Tsipy

2015 "The Pregnancy Manifesto: Notes on How to Extract Reproduction from the Petri Dish." Medical Anthropology 34, no. 3: 274-89. https://doi.org/10.1080/0145 9740.2015.1023952.

Jordan, Brigitte

1993 Birth in Four Cultures: A Crosscultural Investigation of Childbirth in Yucatan, Holland, Sweden, and the United States. 4th ed. Revised and expanded by Robbie DavisFloyd. Long Grove, Ill.: Waveland. Originally published in 1978.

Kapsalis, Terri

1997 Public Privates: Performing Gynecology from Both Ends of the Speculum. Durham, N.C.: Duke University Press.

Kline, Wendy

2016 "The Little Manual That Started a Revolution: How Hippie Midwifery Became Mainstream.” In Groovy Science: Knowledge, Innovation, and American Counterculture, edited by David Kaiser and W. Patrick McCray, 172-206. Chicago: University of

Knight, Kelly Ray Chicago Press.

2015 addicted.pregnant.poor. Durham, N.C.: Duke University Press.

Lock, Margaret, and Judith Farquhar, eds.

2007 Beyond the Body Proper: Reading the Anthropology of Material Life. Durham, N.C.: Duke University.

Lock, Margaret, and Patricia A. Kaufert, eds.

1998 Pragmatic Women and Body Politics. Cambridge, UK: Cambridge University. 
Lyerly, Anne Drapkin

2006 "Shame, Gender, Birth.” Hypatia 21, no. 1: 101-18. https://doi.org/10.1111/ j.1527-2001.2006.tb00967.x.

MacCormack, Carol, and Marilyn Strathern, eds.

1980 Nature, Culture and Gender. Cambridge, UK: Cambridge University Press.

Macdonald, Margaret

2006 "Gender Expectations: Natural Bodies and Natural Births in the New Midwifery in Canada." Medical Anthropology Quarterly 20, no. 2: 235-56.

Martin, Emily

2001 The Woman in the Body: A Cultural Analysis of Reproduction. Boston: Beacon. Originally published in 1987.

Martin, Nina, ProPublica, Emma Cillekens, and Alessandra Freitas

2017 "Lost Mothers." ProPublica, July 17. https://www.propublica.org/article/lostmothers-maternal-health-died-childbirth-pregnancy.

Masco, Joseph

2006 The Nuclear Borderlands: The Manhattan Project in Post-Cold War New Mexico. Princeton, N.J.: Princeton University.

Miller, Kristin

2013 "Postcards from the Future: Utopian North, Dystopian South.” Boom: The Journal of California 3, no. 4: 12-26. https://doi.org/10.1525/boom.2013.3.4.12.

Morris, Theresa

2013 Cut It Out: The C-Section Epidemic in America. New York: New York University.

Morton, Christine H.

2009 “Where Are the Ethnographies of US Hospital Birth?” Anthropology News 50, no. 3:

Odent, Michel 10-11. https://doi.org/10.1111/j.1556-3502.2009.50310.x.

2014 Childbirth and the Evolution of Homo Sapiens. London: Pinter and Martin.

Ortner, Sherry B.

1974 "Is Female to Male as Nature Is to Culture?" In Women, Culture, and Society, edited by Michelle Zimbalist Rosaldo and Louise Lamphere, 67-88. Stanford, Calif.: Stanford University.

Pastor, Manuel

2018 State of Resistance: What California's Dizzying Descent and Remarkable Resurgence Mean for America's Future. New York: The New Press.

Paxson, Heather

2004 Making Modern Mothers: Ethics and Family Planning in Urban Greece. Berkeley: University of California Press.

Rapp, Rayna

2001 "Gender, Body, Biomedicine: How Some Feminist Concerns Dragged Reproduction to the Center of Social Theory." Medical Anthropology Quarterly 15,

Roberts, Dorothy no. 4: 466-77. https://doi.org/10.1525/maq.2001.15.4.466.

1997 Killing the Black Body: Race, Reproduction, and the Meaning of Liberty. New York: Pantheon.

Sadjadi, Sahar

2019 "Deep in the Brain: Identity and Authenticity in Pediatric Gender Transition." Cultural Anthropology 34, no. 1: 103-29. https://doi.org/10.14506/ca34.1.10.

Sakala, Carol, Eugene R. Declercq, Jessica M. Turon, and Maureen P. Corry

2016 Listening to Mothers in California. National Partnership for Women and Families. Sanabria, Emilia http://www.nationalpartnership.org/our-work/health/listening-to-mothers-ca/.

2016 Plastic Bodies: Sex Hormones and Menstrual Suppression in Brazil. Durham, N.C.: Duke University Press. 
Sandelowski, Margarete

2000 Devices and Desires: Gender, Technology, and American Nursing. Chapel Hill: University of North Carolina Press.

Schüll, Natasha Dow

2016 "Data for Life: Wearable Technology and the Design of Self-Care." BioSocieties 11, Sufrin, Carolyn no. 3: 1-17. https://doi.org/10.1057/biosoc.2015.47.

2017 Jailcare: Finding the Safety Net for Women behind Bars. Berkeley: University of California Press.

SVIRS (Silicon Valley Institute for Regional Studies)

2017 Silicon Valley Index. San Jose, Calif: Silicon Valley Institute for Regional Studies. https://siliconvalleyindicators.org/download-the-2017-index/.

n.d. "Population Share by Race/Ethnicity: Santa Clara and San Mateo Counties." Silicon Valley Indicators. Accessed August 27, 2020. https://siliconvalleyindicators.org/ data/people/talent-flows-diversity/racial-and-ethnic-composition/population-

Turner, Fred share-by-race-ethnicity/.

2008 From Counterculture to Cyberculture: Stewart Brand, the Whole Earth Network, and the Rise of Digital Utopianism. Chicago: University of Chicago Press.

U.S. Department of Health and Human Services

2011 The Surgeon General's Call to Action to Support Breastfeeding. Washington, D.C.: U.S. Department of Health and Human Services, Office of the Surgeon General. https://www.cdc.gov/breastfeeding/resources/calltoaction.htm.

Villalobos, Ana

2014 Motherload: Making It All Better in Insecure Times. Oakland: University of California Press.

Villarosa, Linda

2018 "Why America's Black Mothers and Babies Are in a Life-or-Death Crisis." New York Times Magazine, April 11. https://www.nytimes.com/2018/04/11/magazine/ black-mothers-babies-death-maternal-mortality.html.

Walker, Richard A.

2018 Pictures of a Gone City: Tech and the Dark Side of Prosperity in the San Francisco Bay Area. Oakland, Calif.: PM Press.

Wendland, Claire L.

2008 "The Vanishing Mother: Cesarean Section and 'Evidence-Based Obstetrics." Medical Anthropology Quarterly 21, no. 2: 218-33. https://doi.org/10.1525/MAQ. 2007.21.2.218. 